\title{
Research
}

\section{Use of alarm features in referral of febrile children to the emergency department:}

\author{
an observational study
}

\begin{abstract}
\section{Background}

The diagnostic value of alarm features of serious infections in low prevalence settings is unclear.
\end{abstract}

\section{Aim}

To explore to what extent alarm features play a role in referral to the emergency department (ED) by GPs who face a febrile child during out-ofhours care.

\section{Design and setting}

Observational study using semi-structured routine clinical practice data of febrile children ( $<16$ years) presenting to GP out-of-hours care.

\section{Method}

Logistic regression analyses were performed to assess the association between alarm features of serious infections (selected from two guidelines and one systematic review) and referral to the ED. Adherence to the guideline was explored by a $2 \times 2$ contingency table.

\section{Results}

In total 794 (8.1\%) of 9794 eligible patients were referred to the ED. Alarm signs most strongly associated with referral were 'age $<1$ month' 'decreased consciousness', 'meningeal irritation', and 'signs of dehydration'. Nineteen percent of 3424 children with a positive referral indication according to the guideline were referred to the ED. The majority of those not referred had only one or two alarm features present. A negative referral indication was adhered to for the majority of children. Still, in $20 \%$ of referred children, alarm features were absent.

\section{Conclusion}

In contrast to guidance, GPs working in primary out-of-hours care seem more conservative in referring febrile children to the ED, especially if only one or two alarm features of serious infection are present. In addition, in $20 \%$ of referred children, alarm features were absent, which suggests that other factors may be important in decisions about referral of febrile children to the hospital ED.

\section{Keywords}

bacterial infections; child; fever; general practice; infant; referral and consultation; signs and symptoms.

\section{INTRODUCTION}

In primary care, GPs frequently encounter febrile children, who are at risk of serious infections, such as meningitis, sepsis and pyelonephritis, ${ }^{1,2}$ which can lead to morbidity and mortality. ${ }^{3-5}$ The combined prevalence of serious infections in primary care; however, is less than 1\%.6 Therefore GPs have the challenging task of distinguishing between the majority of children who have a low risk of serious infection and the minority at high risk who require further action.

Studies on identifying serious infections in low-prevalence settings are scarce.6-9 Current clinical guidelines supporting GPs in managing febrile children are predominantly based on consensus and evidence from hospital emergency care studies, which lack external validation in low-prevalence settings. ${ }^{7,9}$ The international National Institute for Health and Care Excellence (NICE) guideline for children with feverish illness ${ }^{10,11}$ proposes a traffic light system, which advises referring a child for specialist consultation if either a red or amber (in the absence of a diagnosis and sufficient safety net)' feature is present. Likewise, the Dutch GP guideline for febrile children $^{12}$ also bases its referral advice on the presence of single alarm features, all of which are also classified as 'red' or 'amber' features in the NICE guideline. ${ }^{10}$ In 2010, a systematic review of mainly

R Oostenbrink, $\mathrm{PhD}, \mathrm{MD} ; \mathrm{Y}$ van lerland, $\mathrm{PhD}$ MD; HA Moll, professor; RG Nijman, MSc, MD; Department of General Paediatrics, ErasmusMC Sophia Children's Hospital, Rotterdam, The Netherlands. G Elshout, MSc, MD, Department of General Practice; Y Vergouwe, PhD, Center for Medical Decision Making; J van der Lei, Professor, Department of Medical Informatics, ErasmusMC, Rotterdam, The Netherlands. MY Berger, Professor, Department of General Practice, ErasmusMC, Rotterdam, the Netherlands; Department of General Practice, University Groningen, University Medical Center Groningen, Groningen, the Netherlands. hospital emergency care studies identified many of these alarm features as potentially useful in identifying children at high risk of serious infection. ${ }^{13}$ However, there is still much debate about the diagnostic value of these alarm features in low-prevalence settings. ${ }^{7,8,13}$

This study aimed to explore to what extent alarm features play a role in referral management of GPs who encounter a febrile child in primary out-of-hours care and to what extent GPs adhere to the national guideline's advice on referral.

\section{METHOD}

\section{Study design}

An observational study was performed. Semi-structured, routine clinical practice data were collected of children with fever who had presented to GP out-of-hours care.

\section{Study setting and patient selection}

In the Netherlands, patients should in principle first contact the General Practitioner Cooperative (GPC) for out-ofhours primary care. However, within the total amount of out-of-hours demand, $5 \%$ of patients will present directly to the emergency department (ED) (that is, selfreferral). ${ }^{2}$ Contacts eligible for this study were children aged $<16$ years who had a face-to-face consultation with a GP at the GPC and had fever, defined as:

\section{Address for correspondence}

Rianne Oostenbrink, Department of Genera Paediatrics, Dr. Molewaterplein 60, P0 Box 2060, 3000 CB Rotterdam, The Netherlands.

E-mail: r.oostenbrink@erasmusmc.nl

Submitted: 1 August 2013; Editor's response: 16 October 2013; final acceptance: 8 November 2013.

\section{CBritish Journal of General Practice}

This is the full-length article [published online 30 Dec 2013] of an abridged version published in print. Cite this article as: $\mathbf{B r} \mathbf{J}$ Gen Pract 2014;

DOI: 10.3399/bjgp14X676393 


\section{How this fits in}

The diagnostic value of alarm features of serious infections in low-prevalence settings is unclear. Current guidelines for management of febrile children mainly base their referral advice on the presence of single alarm signs and symptoms. In practice, only $19 \%$ of GPs adhered to the guideline's positive referral advice and $20 \%$ of children referred to the emergency department had no alarm features present. It is recommended that further longitudinal follow-up studies investigate the true and false positives/negatives of current referral management and the different reasons why GPs do or do not refer children to the emergency department. This may provide future guidelines with adequate safetynetting advice to fill the gap of insufficient rule-in or rule-out value reached by clinical alarm signs and symptoms alone.

a) fever reported by parents as the reason for contact;

b) fever within 24 hours prior to contact; or

c) a temperature above $38^{\circ} \mathrm{C}$ measured at the GPC.

Revisits for the same problem within 7 days of the initial presentation were excluded (Figure 1).

\section{Data collection and data extraction process}

The data collection of this study has been described previously. ${ }^{14}$ In summary, data were collected from all GPC contacts in the Rotterdam-Rijnmond district during
March 2008 to February 2009. For the data-extraction process clinical features indicative of a serious infection were derived from the Dutch national GP guideline for febrile children; ${ }^{12}$ the NICE guideline for feverish illness in children; ${ }^{10}$ and a systematic review. ${ }^{13}$ Details on selection of the clinical features were reported previously. ${ }^{11}$ Selected, closely related features were grouped into 18 alarm signs and symptoms of serious infection (Appendix 1). Whether alarm signs and symptoms were 'present', 'absent' or 'not mentioned' in the patient record were manually recoded using a data-entry computer program Delphi XE (version 15.0). Clinical management by the GP was recoded as 'referral to ED (yes/no)'.

\section{Statistical analysis}

Missing data. Since clinical information was obtained from routine practice data, the study had to manage missing values (Table 1). ${ }^{11}$ For the purpose of this study, missing values were dealt with in two ways:

1. Alarm signs and symptoms were assumed to be so relevant that, if present, the GP would document them. Consequently, alarm signs and symptoms 'not mentioned' in the patient record were considered 'absent' (that is, ill appearance, ABC-instability, unconsciousness, drowsy, inconsolable, cyanosis, shortness of breath, meningeal irritation, neurological signs, vomiting and diarrhoea, dehydration, joint or limb problems, and petechial rash).

2. For the remaining alarm signs and symptoms missing values were imputed 10 times using the MICE logarithm (R-Project), ${ }^{15}$ that is, abnormal circulation, signs of urinary tract infection, temperature of $\geq 40^{\circ} \mathrm{C}$, and duration of fever. The imputation model included sex, age, and all alarm signs and symptoms included in the analysis (describing casemix of the population) and the outcome variable 'referral to the ED'. Results of the imputation process are displayed in Appendix 2. Vital signs, such as heart frequency', 'breathing frequency', and 'oxygen saturation', were reported in only $1 \%$ of the patient records and were therefore excluded from the analysis as individual alarming signs.

Association between alarm features and referral management

The study focused on the Dutch national guideline, ${ }^{12}$ which advises to refer a febrile 
Table 1. Characteristics of study population $(n=9794)$

\begin{tabular}{|c|c|c|}
\hline Basic characteristics & & Range \\
\hline Female sex, $n(\%)$ & $4521(46.2)$ & \\
\hline Age in years, median (IQR) & $2.31 .0-4.6$ & $0.02-16$ \\
\hline Temperature at GPC in ${ }^{\circ} C^{a}$, median, IQR & $38.5(37.7-39.1)$ & $35.5-41.3$ \\
\hline Alarm features & $\begin{array}{c}\text { Present } \\
n(\%)\end{array}$ & $\begin{array}{c}\text { Absent } \\
n(\%)\end{array}$ \\
\hline Parental concern ${ }^{a}$ & $1665(17.0)$ & $4(<0.1)$ \\
\hline Ill appearance & $389(4.0)$ & 9405 (96.0) \\
\hline ABC-instability & $1(<0.1)$ & 9793 (>99.9) \\
\hline Unconsciousness & $8(0.1)$ & $9786(99.9)$ \\
\hline Drowsy & $53(0.5)$ & 9741 (99.5) \\
\hline Inconsolable & 384 (3.9) & $9410(96.1)$ \\
\hline Abnormal circulation ${ }^{a}$ & $162(1.7)$ & $2424(24.7)$ \\
\hline Cyanosis & $46(0.5)$ & 9748 (99.5) \\
\hline Shortness of breath & $465(4.7)$ & 9329 (95.3) \\
\hline Meningeal irritation & $55(0.6)$ & 9739 (99.4) \\
\hline Neurological signs & $152(1.6)$ & $9642(98.4)$ \\
\hline Vomiting and diarrhoea & 2073 (21.2) & 7721 (78.8) \\
\hline Dehydration & $96(1.0)$ & 9698 (99.0) \\
\hline Joint or limb problems & $27(0.3)$ & 9767 (99.7) \\
\hline Signs of UTla & $499(5.1)$ & 3467 (35.4) \\
\hline Petechial rash & $34(0.3)$ & 9760 (99.7) \\
\hline Temperature $\geq 40^{\circ} \mathrm{C}^{a}$ & $2462(25.1)$ & $6093(62.2)$ \\
\hline \multicolumn{3}{|l|}{ Duration of fever: ${ }^{a}$} \\
\hline Started today & $2008(20.5)$ & \\
\hline 1 day & $1729(17.7)$ & \\
\hline 2 days & $1228(12.5)$ & \\
\hline 3 days & $1325(13.5)$ & \\
\hline 4 days & $700(7.1)$ & \\
\hline 5 days & $381(3.9)$ & \\
\hline 6 days & 120 (1.2) & \\
\hline$\geq 7$ days & 230 (2.3) & \\
\hline Outcome measure & $\begin{array}{l}\text { Yes } \\
n(\%)\end{array}$ & $\begin{array}{l}\text { No } \\
n(\%)\end{array}$ \\
\hline Referral to ED & $794(8.1)$ & 9000 (91.9) \\
\hline
\end{tabular}

$A B C$-instability = respiratory or circulatory insufficiency. $E D=$ emergency department. GPC = General Practitioner Cooperative. $I Q R=$ interquartile range. UTI = urinary tract infection. ${ }^{a}$ Missing values for: temperature at GPC: 6426 (65.6\%); parental concern: 8125 (83.0\%); abnormal circulation: 7208 (73.6\%); signs of UTI: 5828 (59.5\%); temperature $\geq 40^{\circ} \mathrm{C}$ : 1239 (12.7\%); duration of fever: 2073 (21.1\%). child to secondary care if at least one alarm feature is present. Guideline definitions for 'age <1 month', 'abnormal circulation', 'meningeal irritation', 'petechial rash', and 'signs of dehydration' matched with those of the dataset. For the other guideline features, alarm signs and symptoms were combined or best proxies used in the dataset. The study selected age between 1-3 months' as a proxy for the guideline feature age between 1-3 months and fever of unknown origin', 'ill appearance and/or inconsolable and/or ABC-instability (that is, respiratory or circulatory insufficiency)' as a proxy for 'ill appearance', 'unconsciousness and/or drowsy' as a proxy for 'decreased consciousness', 'vomiting and diarrhoea' as a proxy for 'persistent vomiting', and 'shortness of breath and/or cyanosis' as a proxy for 'severe shortness of breath'.

Logistic regression analyses was performed to assess the association between referral to the ED and the presence of alarm features selected from the national guideline. Additionally, the study included alarm features selected from the NICE guideline ${ }^{10}$ and systematic review, ${ }^{13}$ that is, 'neurological signs', 'joint or limb problems', 'signs of urinary tract infection', 'temperature $\geq 40^{\circ} \mathrm{C}$ ', and 'duration of fever'. For the multivariable analyses, the study used multiple imputed data, as much relevant clinical information would be lost by performing a complete case analysis only.

Finally, the study assessed GPs' adherence to the national guideline by constructing a two-by-two contingency table, that is, referral indication according to guideline versus observed referral to the ED. Statistical analyses were performed with IBM SPSS Software version (20.0).

\section{RESULTS}

Characteristics of the study population are displayed in Table 1. In total, 794 (8.1\%) of 9794 contacts were followed by a referral to the ED. Frequencies of individual alarm signs and symptoms were generally higher among referred than non-referred children (Table 2). Among the national guideline's alarm features, 'age < 1 month', 'decreased consciousness', 'meningeal irritation', and 'signs of dehydration' were most strongly associated with referral. Together, the national guideline-specific alarm features explained $40 \%$ of the variability in referral by the GP. Taking into account the alarm features selected from the NICE guideline and the systematic review additionally, the explained variability increased up to maximally $45 \%$.

\section{Adherence to the national guideline}

Table 3 displays guideline adherence by GPs. Overall, 3424 (35\%) of 9794 eligible contacts had a positive referral indication, that is, at least one of the guideline-specific alarm features was present. Among these, $633(19 \%)$ of 3424 children were referred to the ED. Among the children with a negative referral indication, that is, none of the guideline-specific alarm features were present, the GP followed the guideline in $6209(97 \%)$ of 6370 contacts. However, 
Table 2. Association between the presence of alarm features and referral by the GP

\begin{tabular}{|c|c|c|c|c|c|c|c|}
\hline $\begin{array}{l}\text { Alarm features } \\
\text { according to } \\
\text { national guidance }\end{array}$ & & $\begin{array}{l}\text { NICE traffic } \\
\text { light system }\end{array}$ & $\begin{array}{c}\text { Positive } L R>5 \\
\text { in systematic } \\
\text { review }^{12}\end{array}$ & $\begin{array}{c}\text { Referred } \\
\text { (n=794; } n[\%]]\end{array}$ & $\begin{array}{c}\text { Non-referred } \\
(n=9000 ; n[\%])\end{array}$ & $\begin{array}{l}\text { Univariate } \mathrm{OR}^{\mathrm{a}} \\
\text { OR }(95 \% \mathrm{CI})\end{array}$ & $\begin{array}{l}\text { Adjusted OR, } \\
\text { OR }(95 \% \mathrm{CI})\end{array}$ \\
\hline Age $<1$ month & Yes & Red & No & $25(3.1)$ & $7(0.1)$ & 42 (18 to 97 ) & $64(26$ to 161$)$ \\
\hline Age $1-3$ months & Yes & Red & No & 74 (9.3) & $98(1.1)$ & $9.4(6.8$ to 13$)$ & 11 (7.8 to 17$)$ \\
\hline IIl appearance & Present & Red & Yes & 255 (32) & $463(5.1)$ & $8.7(7.3$ to 10$)$ & $6.8(5.4$ to 8.6$)$ \\
\hline $\begin{array}{l}\text { Decreased } \\
\text { consciousness }\end{array}$ & Present & Red & Yes & $53(6.7)$ & $4(<0.1)$ & 161 (58 to 446$)$ & 134 (45 to 399) \\
\hline Abnormal circulation & Present & Red & Yes & $71(25)$ & $91(4)$ & 8.1 (5.7 to 11$)$ & 3.9 (2.4 to 6.4$)$ \\
\hline Persistent vomiting & Present & $\begin{array}{c}\text { Red } \\
\text { (if bile-stained) }\end{array}$ & No & 231 (29) & 1842 (21) & $1.6(1.4$ to 1.9$)$ & 1.3 (1.1 to 1.7$)$ \\
\hline Petechial rash & Present & Red & Yes & $15(1.9)$ & $19(0.2)$ & 9.1 (4.6 to 18$)$ & 12 (5.3 to 28 ) \\
\hline Meningeal irritation & Present & Red & Yes & $49(6.2)$ & $6(0.1)$ & 99 (42 to 231) & 90 (36 to 229) \\
\hline $\begin{array}{l}\text { Severe shortness } \\
\text { of breath }\end{array}$ & Present & Amber/red & Yes & 213 (27) & 270 (3.0) & 12 (9.7 to 15$)$ & 12 (8.9 to 15$)$ \\
\hline $\begin{array}{l}\text { Signs of dehydration } \\
\text { (all ages) }\end{array}$ & Present & Amber/red & No & 78 (9.8) & $18(0.2)$ & 54 (32 to 91) & 41 (22 to 77 ) \\
\hline
\end{tabular}

within the total group of referred contacts, $161(20 \%)$ of 794 children had no guidelinespecific alarm feature present.

Table 4 shows the number of alarm features present in children with a positive referral indication. The majority of children for whom the GP overruled the guideline's advice, that is, decided not to refer the child, had one or two alarm features present. When three or more alarm features were present, nearly all children were referred. Alarm features that GPs predominantly overruled were 'vomiting', 'ill appearance', 'abnormal circulation', and 'shortness of breath'.

\section{DISCUSSION}

Summary

GPs adhered to a positive referral advice

\section{Table 3. GPs' referral management and guideline adherence ${ }^{12}$}

\begin{tabular}{l}
$\begin{array}{l}\text { Referral indication accordin } \\
\text { to national guidance }\end{array}$ \\
\hline Yes $(\%$ of total) \\
No $(\%$ of total)
\end{tabular}

\begin{tabular}{ccc}
\multicolumn{2}{c}{ Observed in practice } & Total \\
\cline { 1 - 2 } Referred $^{\mathbf{b}}$ & Not referred & $3424(35)$ \\
$633(19)$ & 2791 & $6370(65)$ \\
$161(3)$ & 6209 & $9794(100)$ \\
$794(8.1)$ & 9000 &
\end{tabular}

aefined as the presence of at least one of the following alarm features: age < 1 month, age 1-3 months with fever of unknown origin, ill appearance, decreased consciousness, abnormal circulation, persistent vomiting, petechial rash, meningeal irritation, severe shortness of breath, and signs of dehydration. ${ }^{b} 161$ (20\%) of 794 contacts were referred to the emergency department without an alarm sign present (that is, no referral indication by the guideline). by the national guideline in only $19 \%$ of the out-of-hours consultations. If only one or two guideline-specific alarm features were present, GPs seemed to be more conservative in referring febrile children to the ED. Alarm features most strongly associated with referral were age $<1$ month', 'decreased consciousness', 'meningeal irritation', and 'signs of dehydration', and 'joint or limb problems'. Even though a negative referral advice by the guideline was adhered to in nearly all of the consultations, $20 \%$ of the children referred to the ED had no alarm feature present. This may indicate that for a considerable group of children, GPs base their referral decisions on other reasons than the presence of alarm features.

\section{Strengths and limitations}

To the best of the study's knowledge, this is the first study to provide an insight into the association between guideline and literature-based alarm features and GP' referral management in primary out-ofhours care practice.

Similar to the international NICE guideline for febrile children, the Dutch national guideline bases its referral advice on the presence of single alarm features, all of which are classified as 'red' or 'amber' features in the NICE guideline as well.

For this study a large, multicultural, urban cohort of nearly 10000 febrile children was used, who presented to primary out-of-hours 


\section{Table 4. Alarm features among febrile children with a referral indication according to national guidance ${ }^{12}$}

\begin{tabular}{lcc} 
& $\begin{array}{c}\text { Referred } \\
(\boldsymbol{n}=633)\end{array}$ & $\begin{array}{c}\text { Not referred } \\
(\boldsymbol{n}=\mathbf{2 7 9 1 )}\end{array}$ \\
\hline Total number of alarm features present & $\boldsymbol{n}(\%)$ & $\boldsymbol{n}(\%)$ \\
\hline 1 & $264(42)$ & $2456(88)$ \\
2 & $214(34)$ & $304(11)$ \\
3 & $118(19)$ & $29(1.0)$ \\
4 & $33(5.2)$ & $2(<0.1)$ \\
5 & $4(0.6)$ & $0(0)$ \\
\hline Age <1 month & $\boldsymbol{n ( \% )}$ & $\boldsymbol{n}(\%)$ \\
Age 1-3 months & $25(4.0)$ & $7(0.3)$ \\
III appearance & $74(12)$ & $98(3.5)$ \\
Decreased consciousness & $255(40)$ & $463(17)$ \\
Abnormal circulation & $53(8.4)$ & $4(0.1)$ \\
Vomiting & $205(32)$ & $431(15)$ \\
Petechial rash & $231(37)$ & $1842(66)$ \\
Meningeal irritation & $15(2.4)$ & $19(0.7)$ \\
Severe shortness of breath & $49(7.8)$ & $6(0.2)$ \\
Signs of dehydration & $213(34)$ & $270(9.7)$ \\
\hline
\end{tabular}

alarm features according to the national guideline: age $<1$ month, age 1-3 months with fever of unknown origin, ill appearance, decreased consciousness, abnormal circulation, persistent vomiting, petechial rash, meningeal irritation, severe shortness of breath, and signs of dehydration. care. As GPCs function as acute primary care facilities and patients can present on their own initiative, the study believes that this population is likely to be generalisable to other large-scale out-of-hours primary care populations and may be extrapolated to children presenting to paediatric acute assessment units in settings with a low prevalence of serious infections.

As prospective data collection in lowprevalence settings is difficult, the study made use of routine clinical practice data. Consequently, alarm features not mentioned' in the patient record could either mean 'not present' or 'not looked at by the physician'. It can be assumed that GPs have carefully documented alarm features to either justify their decision to refer a child or to ensure that their reasons for not referring a child were clear. In a consensus meeting, it was decided to use a multiple imputation strategy to limit the amount of clinical information missing and to best approximate true values. A sensitivity analysis on complete cases revealed no major differences in outcomes (data not shown). Therefore, the study assumes the verification bias to be limited.

\section{Comparison with existing literature}

Several individual alarm features have been demonstrated to have potential value in identifying ('ruling-in') serious infections in children. ${ }^{13}$ However, their applicability, depends on the setting-specific prevalence of disease. Taking into account the low probability of serious infection in primary care (approximately 1\%), the majority of individual alarm features will only raise the posterior probability to about 10\% when present. ${ }^{13}$ As these results were only based on a single primary care study, which lacks external validation, their generalisability to and diagnostic impact in other low-prevalence populations may be questionable. ${ }^{9,16}$

Both the Dutch GP guideline ${ }^{12}$ and the international NICE guideline ${ }^{10}$ base their referral advice on the presence of single alarm features. In the study, it was observed that if one should follow the national guideline, $35 \%$ of all children consulted should be referred. Comparable results were reported by others, who validated the Dutch as well as the NICE guideline in lowprevalence ${ }^{17}$ and intermediate-prevalence populations. ${ }^{17,18}$ They also found that 16\% to $99 \%$ of the children consulted received positive referral advice. Consequently, if one were to follow the guidelines' advice, most children with a serious infection would be referred, yielding high sensitivities (range 81-100\%). However, as the prevalence of serious infections in primary care is only about $1 \%$, an enormous group of children would be referred unnecessarily (false positives), resulting in (very) low specificities (range 1-85\%). From a safety perspective, this may seem a valid approach; however, the disadvantage may be a considerable overload of children who present at the ED without a serious infection. Besides, such unnecessary referrals may cause harm to children with minor illness through crossinfection with more serious conditions, as well as distress to children and their families.

Interestingly, in clinical practice, the study observed that GPs decided to refer only $19 \%$ of the patients with a positive referral indication, of whom the majority had three or more alarm features present. 'Meningeal irritation' and 'decreased consciousness' were nearly never neglected as alarm signs, whereas 'ill appearance' and 'abnormal circulation' were quite often overruled. This may suggest that some features have a broader clinical range in primary care than in high-prevalence settings, where these signs and symptoms were identified as important indicators of serious infection. ${ }^{13}$ From these results, it seems that GPs already apply a certain threshold above 


\section{Funding}

This study was funded by an unrestricted grant from European Container Terminals BV, Rotterdam, The Netherlands.

\section{Ethical approval}

The institution's medical ethics committee reviewed the study and the requirement for informed consent was waived (MEC2012-378).

\section{Provenance}

Freely submitted; externally peer reviewed.

\section{Competing interests}

The authors have declared no competing interests.

\section{Acknowledgements}

We would like to thank M. de Wilde for his support in data processing and data management. We would like to thank $T$. Krecinic, Z. Gocmen, M. Hofhuis and M. Rotsteeg for their contrinbution to data management.

\section{Discuss this article}

Contribute and read comments about this article: www.bjgp.org/letters which they feel their referral is grounded, that is, they balance the risk between false positive and false negative outcomes. They also seem to share the opinion that combinations of alarm features may do better in ruling in serious infections than single features alone. In line with this finding, others have recently reported on the diagnostic value of three or more 'red features' of the NICE traffic light system (E Kerkhof, personal communication, 2013). Unfortunately, the posterior probability of disease was still unsatisfactorily raised to a maximum of about $10 \%$ in low-prevalence settings specifically.

Should we then better shift our focus towards ruling out serious infections in lowprevalence settings? Previous reports have indicated that individual alarm features have insufficient rule-out value on their own. ${ }^{6,713}$ However, combinations of absent alarm features may significantly decrease the probability of disease. ${ }^{13}$ For the majority of children without alarm features present, the GPs in the study seemed quite confident about the absence of a serious infection. However, the difficulty lies in determining the threshold of exactly how many alarm features must be absent to sufficiently rule out serious febrile illness. Clinical prediction rules may, alongside guidelines, help physicians to identify children at low risk of disease. ${ }^{19-25}$ The only clinical prediction rule developed for primary care specifically showed a promising high sensitivity and low negative likelihood ratio at derivation; 6 however, it lacked generalisability on external validation in other low-prevalence populations. ${ }^{17}$ In addition, another study has shown that other clinical prediction rules developed for hospital emergency care were of limited use in the primary outof-hours care setting as well.

Finally, another study demonstrated that $20 \%$ of the referred children had no alarm feature present. This suggests that other reasons seem important in GPs' referral decisions.

\section{Implications for research and practice}

Even though the exact harms and benefits of currently used clinical guidelines should be further elucidated, the question arises whether it is possible to develop a guideline with only clinical features that sufficiently rule in or rule out serious infections in children consulting in primary care. Future studies may answer this question by exploring the alternative reasons why GPs refer a febrile child; the potentially additive value of inflammatory marker point-of-care tests, such as C-reactive protein to guidelines or clinical prediction rules, as these have shown promising results in adult primary care studies as well as studies performed at paediatric $\mathrm{EDs}^{26-28}$ and the disease course over time in longitudinal follow-up studies, to provide future guidelines with adequate safetynetting advice to fill the gap of insufficient rule-in or rule-out value reached by clinical alarm features alone. 


\section{REFERENCES}

1. Bruijnzeels MA, Foets M, van der Wouden JC, et al. Everyday symptoms in childhood: occurrence and general practitioner consultation rates. $\mathrm{Br} J \mathrm{Gen}$ Pract 1998; 48(426): 880-884.

2. Moll van Charante EP, van Steenwijk-Opdam PC, Bindels PJ. Out-of-hours demand for GP care and emergency services: patients' choices and referrals by general practitioners and ambulance services. BMC Fam Pract 2007; 8: 46.

3. Bateman SL, Seed PC. Procession to pediatric bacteremia and sepsis: covert operations and failures in diplomacy. Pediatrics 2010; 126(1): 137-150.

4. Prayle A, Atkinson M, Smyth A. Pneumonia in the developed world. Paediatr Respir Rev 2011; 12(1): 60-69.

5. Sáez-Llorens X, McCracken GH Jr. Bacterial meningitis in children. Lancet 2003; 361(9375): 2139-2148.

6. Van den Bruel A, Aertgeerts B, Bruyninckx R, et al. Signs and symptoms for diagnosis of serious infections in children: a prospective study in primary care. Br J Gen Pract 2007; 57(540): 538-546.

7. Thompson M, Van den Bruel A, Verbakel J, et al. Systematic review and validation of prediction rules for identifying children with serious infections in emergency departments and urgent-access primary care. Health Technol Assess 2012; 16(15): 1-100.

8. Buntinx F, Mant D, Van den Bruel A, et al. Dealing with low-incidence serious diseases in general practice. Br J Gen Pract 2011; 61(582): 43-46.

9. Oostenbrink R, Thompson M, Steyerberg EW, et al. Barriers to translating diagnostic research in febrile children to clinical practice: a systematic review. Arch Dis Child 2012; 97(7): 667-672.

10. National Institute for Health and Care Excellence. Feverish illness in children: Assessment and initial management in children younger than 5 years. Clinical guidelines, CG47. London: NICE, 2007.

11. National Institute for Health and Care Excellence. Feverish illness in children. London: NICE, 2013.

12. Berger MY, Boomsma LJ, Albeda FW, et al. Guideline: Children with fever [NHG-standaard Kinderen met koorts], 2008. https://mww.nhg.org/standaarden/ samenvatting/kinderen-met-koorts (accessed 2 Dec 2013).

13. Van den Bruel A, Haj-Hassan T, Thompson M, et al. Diagnostic value of clinical features at presentation to identify serious infection in children in developed countries: a systematic review. Lancet 2010; 375(9717): 834-845.

14. Elshout $G$, van lerland $Y$, Bohnen AM, et al. Alarm signs and antibiotic prescription in febrile children in primary care: an observational cohort study. $\mathrm{Br}$ J Gen Pract 2013; 63(612): DOI: 10.3399/bjgp13X669158.

15. Donders AR, van der Heijden GJ, Stijnen T, Moons KG. Review: a gentle introduction to imputation of missing values. J Clin Epidemiol 2006; 59(10): 1087-1091.

16. Reilly BM, Evans AT. Translating clinical research into clinical practice: impact of using prediction rules to make decisions. Ann Intern Med 2006; 144(3): 201-209.

17. Verbakel JY, Van den Bruel A, Thompson M, et al. How well do clinical prediction rules perform in identifying serious infections in acutely ill children across an international network of ambulatory care datasets? BMC Med 2013 11: 10 .

18. De S, Williams GJ, Hayen A, et al. Accuracy of the 'traffic light' clinical decision rule for serious bacterial infections in young children with fever: a retrospective cohort study. BMJ 2013; 346: f866.

19. Berger RM, Berger MY, van Steensel-Moll HA, et al. A predictive model to estimate the risk of serious bacterial infections in febrile infants. Eur J Pediatr 1996; 155(6): 468-473.

20. Bleeker SE, Derksen-Lubsen G, Grobbee DE, et al. Validating and updating a prediction rule for serious bacterial infection in patients with fever without source. Acta Paediatr 2007; 96(1): 100-104.

21. Brent AJ, Lakhanpaul $M$, Thompson $M$, et al. Risk score to stratify children with suspected serious bacterial infection: observational cohort study. Arch Dis Child $2011 ;$ 96(4): 361-367

22. Craig JC, Williams GJ, Jones M, et al. The accuracy of clinical symptoms and signs for the diagnosis of serious bacterial infection in young febrile children: prospective cohort study of 15781 febrile illnesses. BMJ 2010; 340: c1594.

23. Pantell RH, Newman TB, Bernzweig J, et al. Management and outcomes of care of fever in early infancy. JAMA 2004; 291(10): 1203-1212.

24. Thompson M, Coad N, Harnden A, et al. How well do vital signs identify children with serious infections in paediatric emergency care? Arch Dis Child 2009; 94(11): 888-893.

25. Young Infants Clinical Signs Study Group. Clinical signs that predict severe illness in children under age 2 months: a multicentre study. Lancet 2008; 371(9607): 135-142

26. Van den Bruel A, Thompson MJ, Haj-Hassan T, et al. Diagnostic value of laboratory tests in identifying serious infections in febrile children: systematic review. BMJ 2011; 342: d3082

27. Cals JW, Butler CC, Hopstaken RM, et al. Effect of point of care testing for $\mathrm{C}$ reactive protein and training in communication skills on antibiotic use in lower respiratory tract infections: cluster randomised trial. BMJ 2009; 338: b1374.

28. Cals JW, Chappin FH, Hopstaken RM, et al. C-reactive protein point-ofcare testing for lower respiratory tract infections: a qualitative evaluation of experiences by GPs. Fam Pract 2010; 27(2): 212-218. 


\section{Appendix 1. Grouping of alarm features for serious infection}

\begin{tabular}{|c|c|}
\hline $\begin{array}{l}\text { Grouped alarm features } \\
\text { las coded in the GPC-database) }\end{array}$ & Total selection of alarm features \\
\hline Parental concern & Parental concern \\
\hline Ill appearance & $\begin{array}{l}\text { Clinician's instinct something is wrong } \\
\text { Clinically ill appearance }\end{array}$ \\
\hline ABC-instability & Respiratory or circulatory insufficiency \\
\hline Unconsciousness & Unconsciousness \\
\hline Drowsy & $\begin{array}{l}\text { Child is drowsy } \\
\text { Somnolence } \\
\text { Reactivity/functional status (decreased) } \\
\text { Hypotonia }\end{array}$ \\
\hline Inconsolable & $\begin{array}{l}\text { Child is inconsolable } \\
\text { Irritability } \\
\text { Changed crying pattern } \\
\text { Child is moaning }\end{array}$ \\
\hline Abnormal circulation & $\begin{array}{l}\text { Abnormal skin colour (pale, mottled, ashen) } \\
\text { Capillary refill time }>2 \mathrm{sec} \\
\text { Tachycardia (APLS) }\end{array}$ \\
\hline Cyanosis & $\begin{array}{l}\text { Cyanosis } \\
\text { Oxygen saturation }<95 \%\end{array}$ \\
\hline Shortness of breath & $\begin{array}{l}\text { Shortness of breath } \\
\text { Nasal flaring } \\
\text { Rapid breathing } \\
\text { Changed breathing pattern }\end{array}$ \\
\hline Meningeal irritation & $\begin{array}{l}\text { Neck stiffness } \\
\text { Bulging fontanelle }\end{array}$ \\
\hline Neurological signs & $\begin{array}{l}\text { Focal neurological signs } \\
\text { Paresis/paralysis } \\
\text { Seizures/fits }\end{array}$ \\
\hline Vomiting \& diarrhoea & $\begin{array}{l}\text { Vomiting ( }>2 x \text { in disease period) } \\
\text { Diarrhoea ( }>2 x \text { in disease period) }\end{array}$ \\
\hline Dehydration & $\begin{array}{l}\text { Dry mucous membranes } \\
\text { Sunken eyes } \\
\text { Decreased skin elasticity } \\
\text { Reduced urine output } \\
\text { Hypotension (APLS) } \\
\text { Poor feeding }\end{array}$ \\
\hline Joint or limb problems & $\begin{array}{l}\text { Swelling of limb or joint } \\
\text { Non-weight bearing limb } \\
\text { Not using an extremity }\end{array}$ \\
\hline Signs of urinary tract infection & $\begin{array}{l}\text { Urinary frequency } \\
\text { Dysuria } \\
\text { Tummy ache (without other focus for fever) }\end{array}$ \\
\hline Petechial rash & $\begin{array}{l}\text { Petechial rash } \\
\text { Purpura }\end{array}$ \\
\hline Temperature $\geq 40^{\circ} \mathrm{C}$ & Measured at home or at GPC \\
\hline Duration of fever & Duration of fever $\left(>38.0^{\circ} \mathrm{C}\right)$ in days \\
\hline
\end{tabular}




\section{Appendix 2. Results of the multiple imputation process}

\begin{tabular}{lcc} 
Alarm features & $\begin{array}{c}\text { Present } \\
\boldsymbol{n}(\%)\end{array}$ & $\begin{array}{c}\text { Absent } \\
\boldsymbol{n}(\%)\end{array}$ \\
\hline Temperature at GPC in ${ }^{\circ} \mathrm{C}$, mean (SE) & $38.4(0.02)$ & $9158(93.5)$ \\
Abnormal circulation & $636(6.5)$ & $8581(87.6)$ \\
Signs of UTI & $1213(12.4)$ & $6983(71.3)$ \\
Temperature $\geq 40^{\circ} \mathrm{C}$ & $2811(28.7)$ & \\
Duration of fever: & & \\
Started today & $2560(26.1)$ & \\
1 day & $2199(22.5)$ & \\
2 days & $1543(15.8)$ & \\
3 days & $1669(17.0)$ & \\
4 days & $8859.0)$ & \\
5 days & $451(4.6)$ & \\
6 days & $1541.6)$ & \\
$\geq 7$ days & $3333.4)$ &
\end{tabular}

Missing values were imputed 10 times with MICE (R-project) for the alarm features 'Temperature at GPC: Abnormal circulation', 'Signs of UTI', 'Temperature $\geq 40^{\circ} \mathrm{C}$ ', and 'Duration of fever'. All other alarming signs reported had no missing data and frequencies are displayed in Table 1. 